\title{
A NOVEL APPROACH OF MEMBRANE ELECTRODE ASSEMBLY FOR APPLICATION IN MICROBIAL FUEL CELL
}

\author{
S. Mulijani ${ }^{1, *}$, G. Syahbirin ${ }^{1}$ and A.Wulanawati ${ }^{1}$ \\ ${ }^{1}$ Department of Chemistry, Faculty of Mathematics and Natural Sciences, Bogor Agricultural \\ University, Bogor-16680, Indonesia \\ *E-mail : janism67@gmail.com
}

\begin{abstract}
The development of a composite membrane based inorganic and organic polymer gained attention among researchers in creating membrane electrode assemblies that contain alternate membranes replacing Nafion for polymer electrolyte fuel cells. However, limitation of incompatibility between electrode and membrane reveals decay and low durability performance of the membrane. The present study recommends fabrication of membrane electrode assembly made of sulfonated polysulfone membrane and composite sulfonated polysulfone- $\mathrm{TiO}_{2}$ based carbon electrode using the hot pressing process. This membrane electrode assembly was utilized in the microbial fuel cell application and its performance was evaluated by measuring proton conductivity and power density. Morphology of membrane was measured by scanning electron microscope. Addition of $\mathrm{TiO}_{2}$ in $\mathrm{MEA}$ enhanced conductivity membrane and power density of MFC.
\end{abstract}

Keywords: Polymer electrolyte fuel cells, nafion, membrane electrode assembly, sulfonated polysulfone, titanium dioxide, microbial fuel cell.

(C) RASĀYAN. All rights reserved

\section{INTRODUCTION}

The Microbial Fuel Cells (MFCs) require knowledge of structural and material modification in electrodes to enhance the performance. In this context, researchers commonly utilized inorganic materials electrodes such as carbon ${ }^{1}$, platinum $(\mathrm{Pt})^{2}$ and graphite/PTFE ${ }^{3}$ in membrane electrode assembly (MEA) research. To address several challenges, MFC construction recently used novel approach of MEA. In general, MEA can be fabricated by a combination of electrodes and membrane with using the hot pressing method. In this process, high temperature and pressure are required to increase the performance of MEA. According to Kim et $a l^{4}$ application of MEA in proton exchange membrane could be maximized power density, achieve effective thermal and water management, and extend fuel cell lifetime and also reduced overpotential and loading of metal in gas diffusion electrode. ${ }^{4}$

In MFCs, organic matter is oxidized by active biocatalyst at anode chamber to produce electrons which are transferred through an external circuit to cathode chamber producing current. At the anode proton will be produced and migrate through the solution across an MEA to the cathode where they combine with oxygen and electrons to form water. As an approach, the MFCs exhibit promising results towards treating wastewater and also simultaneously produces electricity. ${ }^{5}$ In general, several factors significantly affect the performance of MFC such as a separator, electrode material, reactor configuration, electrolyte, microbial species, and others. In addition, the distance between the electrodes ie the anode and the cathode will also affect the power density. Therefore, the development design of membrane electrode assembly (MEA) is very important to enhance the cell performance..$^{6-7}$

In another side, structure and material modification is also required for improving the performance of MFCs, include catalyst and electrodes. In this study fabrication of MEA based sulfonated polysulfone (SPSf) and its composite with $\mathrm{TiO} 2$ will be reported. Investigation of performance MEA in a microbial fuel cell is the main focus of the research. Characteristic of morphology MEA is also evaluated through by Scanning Electron Microscope. 
RASĀYAN J. Chem.

Vol. 11 | No. 1 |151-154 | January - March | 2018

\section{Material and Methods}

\section{EXPERIMENTAL}

Material for MEA was sulfonated polysulfone (SPSf) polymer which was synthesized in the laboratory by direct sulfonation reaction of polysulfone. ${ }^{8}$ Oleum content $65 \% \mathrm{SO}_{3}$ from Merck was used for synthesized SPSf. Polysulfone was procured from Sigma-Aldrich. The membrane electrode assembly (MEA) was fabricated in combined with catalyst ink. The catalyst ink is prepared by mixing $20 \% \mathrm{AgCl} / \mathrm{C}$ catalyst with $5 \%$ SPSf- $\mathrm{TiO}_{2}$ solution with chloroform solvent and stirring to form a paste. The electrode layer is made by applying a catalyst ink mixture on the surface of the carbon paper. The MEA was formed by depositing a previously activated membrane soaked in $3 \% \mathrm{H}_{2} \mathrm{O}_{2}$ for 1 hour and the membrane was immersed in $\mathrm{H}_{2} \mathrm{SO}_{4}$ for 1 hour, after which the membrane was rinsed with deionized water. MEA is coated with two layers of catalyzed electrodes and printed using hot pressing at $140^{\circ} \mathrm{C}$. MEA SPSf without $\mathrm{TiO}_{2}$ is coded by MEA1, and MEA SPSf composited $\mathrm{TiO}_{2} 3 \%$ is coded by MEA2 and MEA SPSf composited $\mathrm{TiO} 25 \%$ is coded by MEA3.

\section{Evaluation of Performance MEA}

Performance of MEA was evaluated by measuring proton conductivity and morphology of surface and cross-section of MEA. Proton conductivity of the prepared membranes were performed using impedance analyzer LCR meter with condition of device are the frequency : $100.00 \mathrm{kHz}$; CC : $1.00 \mathrm{~mA}$; Voltage limitation : $10 \mathrm{mV}$; Range : Auto $10 \Omega$; Open : Off ; Short : Off , Membrane Biophysics Laboratory, Department of Physics, Bogor Agriculture University. The sized membrane $3.4 \mathrm{~cm}^{2}$ is enclosed with two carbon electrodes connected with positive and negative poles on the device. Electrode used is graphite which was activated by immersion into an $\mathrm{HCl}$ solution for 24 hours, then $\mathrm{NaOH} 1 \mathrm{~N}$ for 24 hours, after which the active electrode is rinsed with deionized water and soaked until it will be used. The membrane used was measured in thickness using a digital micrometer where the membrane thickness was directly proportional to the distance between the two carbon (L) electrodes. The value of conduction $(\mathrm{G})$ obtained is converted to a conductivity value per unit of distance called the proton conductivity value $(\sigma)$ through eq.-1.

$$
\sigma=G \frac{L}{A}
$$

\section{MEA application in MFC measurement}

The microbial fuel cell system installed with the MEA was referred to single chamber MFC as a conventional apparatus with membrane separator. The electrode layer is prepared by applying a catalyst ink by mixing $20 \% \mathrm{AgCl} / \mathrm{C}$ catalyst with $5 \%$ sulfonated polysulfone (sPSf)- $\mathrm{TiO}_{2}$ solution with chloroform solvent and stirring to form a paste and mixture on the surface of the carbon paper. The MEA was formed by squeezing the previously activated sPSf membrane in $3 \% \mathrm{H}_{2} \mathrm{O}_{2}$ for 1 hour and then the membrane was immersed in $\mathrm{H}_{2} \mathrm{SO}_{4}$ for 1 hour, after which the membrane was rinsed with deionized water. MEA is coated with two layers of catalyzed electrode and printed using hotpress $\left(140^{\circ} \mathrm{C}\right)$ for 1 minutes. Electrochemically active bacteria were enriched in carbon felt electrode in the anode compartment of a MFC using activated rumen from the municipal rumen wastewater treatment plant (Bogor Indonesia). The $\mathrm{pH}$ of the rumen wastewater was controlled to $7.0 \pm 0.2$. The cathode compartment was fed $\mathrm{K}_{3} \mathrm{Fe}(\mathrm{CN})_{6}$ to control process of the reduction reaction. The current from the MFC was measured using a digital voltammeter.

\section{Morphology of Membrane}

\section{RESULTS AND DISCUSSION}

The cross-section of morphology MEA was evaluated using scanning electron microscope (SEM). The SEM image will reveal of the interface between membrane and electrode of the MEA fabrication. Fig-1 shows the cross-sectional SEM image of composite $\mathrm{SPSf}_{-} \mathrm{TiO}_{2} \mathrm{MEA}$ consisting of carbon electrode which was obtained and compared with that of PSf-MEA. These images reveal thin and uniform catalyst layers, which are formed with a good interface with SPSf-TiO ${ }_{2}$ and PSf membranes, respectively. The thickness of catalyst layers formed onto the membrane through the hot pressing process. Irrespective of the membrane chemical compositions, the catalyst layers are in good contact with both the membranes. Suggesting that 
the hot pressing process is effective in making the good membrane-electrode interface even for different materials. However, Ahn et al. ${ }^{9}$ recommended that range temperature of hot pressing is $210-250^{0} \mathrm{C}$ near the glass transition temperature of hydrocarbon membranes. Although, in the present case, it is not sure if the further increase of temperature would enhance the interfacial bonding in MEA. Our study reveals the hot pressing temperature of $140^{\circ} \mathrm{C}$ can also make good membrane-electrode interface. The preparation of electrode coated onto the decal substrate seems also critical in determining the interfacial bonding between membrane and electrode. An indicator of the success of fabricating the MEA is the formation of catalyst layers and membrane layers seen at the cross-section of the membrane. The carbon catalyst layer is formed and visible white-spaced $\mathrm{TiO}_{2}$ composite. ${ }^{10}$

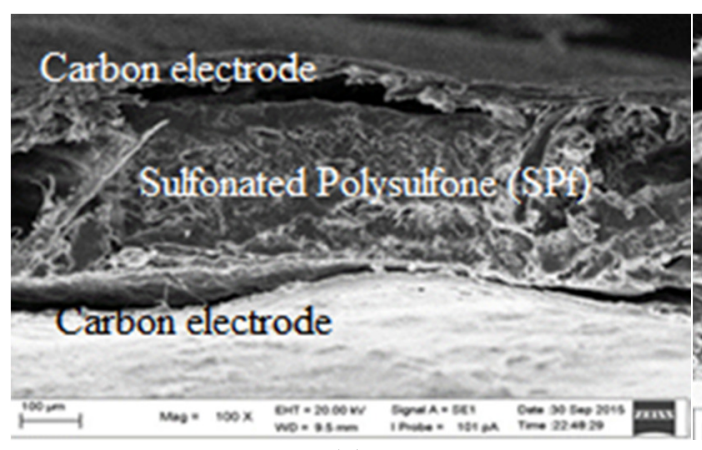

(a)

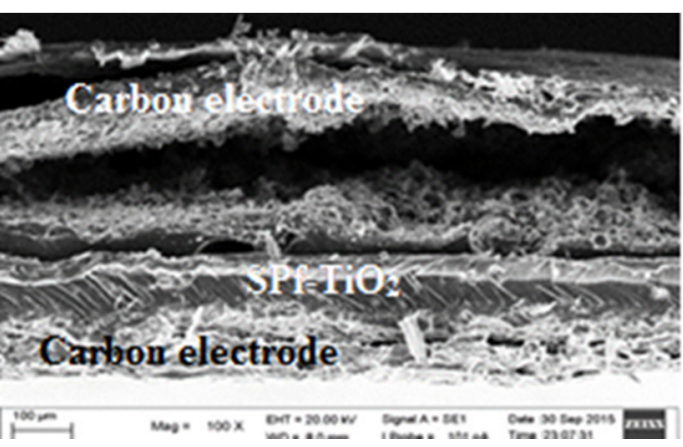

(b)

Fig-1: Cross section SEM image of MEA (a) non composited $\mathrm{TiO}_{2}$ and (b) composited $\mathrm{TiO}_{2}$

\section{Power density and voltage generation in MFC application}

There were obvious differences in the maximum power density with a different type of membrane in the chamber MFC (Fig-2). The highest generated cell voltage and maximum power density MFC was shown by with MEA3 $\left(0.6 \mathrm{~V}, 73.76 \mathrm{~mW} / \mathrm{cm}^{2}\right)$. The reason for maximum power generation with $\mathrm{SPSf}$ can be assumed to the sulfonated functional group in the PSf enhance the proton conductivity.

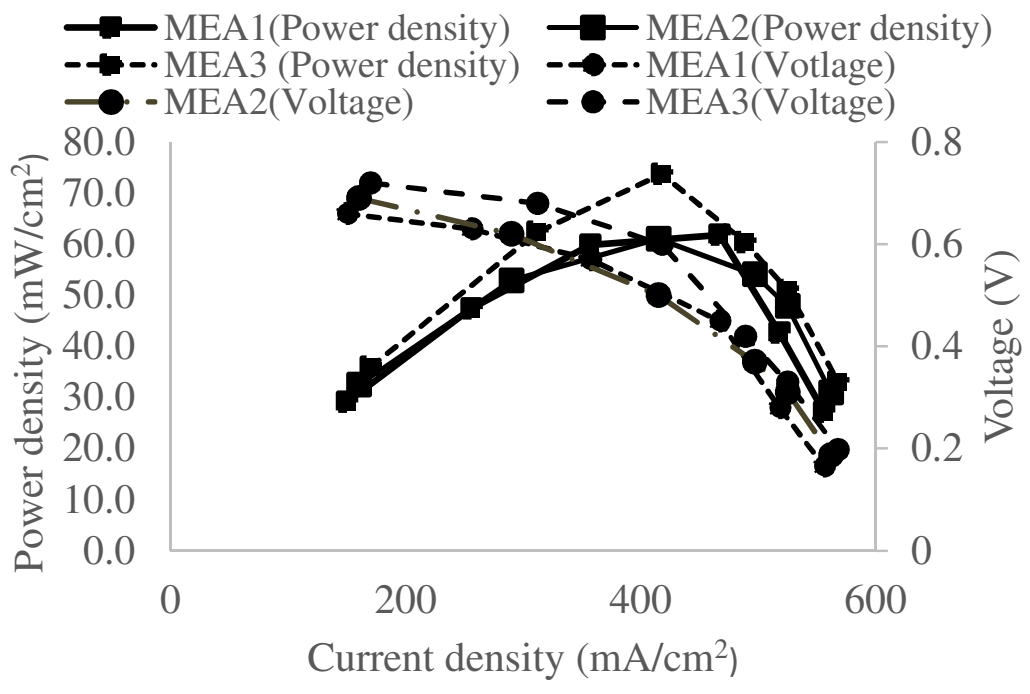

Fig.-2: The voltage and power curves of the MFC

The addition of $\mathrm{TiO}_{2}$ on membrane also affected the performance of the MFC. The MFCs with the addition of $\mathrm{TiO}_{2} 5 \%$ exhibited highest power density compared with MEA1 without $\mathrm{TiO}_{2}$ and $\mathrm{MEA}_{2}$ with $\mathrm{TiO}_{2} 3 \%$. These reflections indicate that addition of $\mathrm{TiO} 2$ will increase power density and also current density. Yao et al. ${ }^{6}$ reported that distance of electrode will affect the value of power density. In this field, the potential 
revealed no substantial conflicts among different types of MEAs. These indicated that proton is not transferred properly by a proton exchange membrane (MEA) from the anode to cathode and it causes the potential of cathode decrease slightly.

\section{Conductivity of Membrane}

Fig-3 exhibits the proton conductivity of membrane MEA is higher than that non MEA. The addition of $\mathrm{TiO}_{2}$ and the sulfonated process of polysulfone will increase the value of proton conductivity. The highest value of proton conductivity is obtained by MEA3 $(7.53 \mathrm{mS} / \mathrm{cm})$. This corresponds with Moon et al. ${ }^{12}$ who reported that sulfonated of polyphenylsulfide (S-PPS) exhibit power density and conductivity higher than that Nafion 117. The possible reason, sulfonated reaction toward benzene structure of polysulfone will increase the hydrophilicity of membrane. Thus, migration of electron and proton in MFC will also increase.

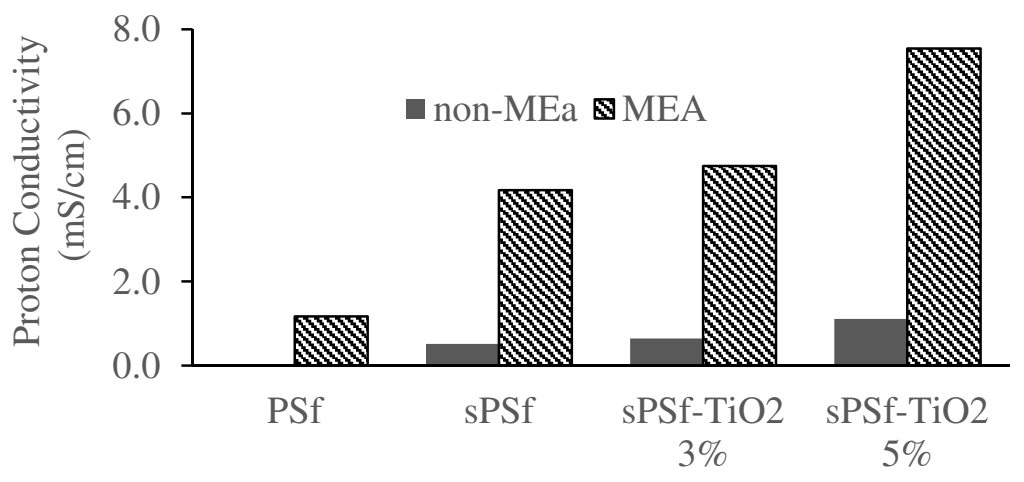

Fig.-3: The proton conductivity of the membranes

\section{CONCLUSION}

Evaluation of performance of MEA for MFCs concludes that MEA SPSf-TiO $25 \%$ exhibited highest generate voltage and power density. Addition of TiO2 and sulfonation of PSf enhanced the performance of MEA in proton transport. SEM analysis revealed that hot pressing and addition of glue enhanced performance bonding of composite polymer in MEA. These results suggest that MEA SPSf $\mathrm{TiO}_{2} 5 \%$ can be a viable alternative to conventional ion exchange separators with enhanced power densities in scaled-up MFC field applications.

\section{ACKNOWLEDGEMENT}

I would like to express our gratitude to Ministry of Research Technology and the Higher Education Republic of Indonesia for valuable funding in the research.

\section{REFERENCES}

1. S. Cheng, H. Liu, and B.E. Logan, Electrochem. Commun. 8, 489 (2006).

2. S. Cheng, L. Hong, and B.E. Logan, Environ. Sci. Technol. 40, 364(2006).

3. T. Zhang, Y. Zeng, S. Chen, X. Ai, and H. Yang, Electrochem. Commun. 9,(3) 349 (2007).

4. M. Kim, M.S. Hyun, G.M. Gadd, G.T. Kim, S.J.Lee and H.J. Kim, Environ. Tech., 30,(4) 329,(2009).

5. A. Parkash, J Microb Biochem Technol 8, 247, (2016).

6. S. Yao, Y. He, Y. Li, and H. Xi, In Proceedings of International Conference on Applied Energy, Taipei City, Taiwan, pp 1947-1951 (2014).

7. O. Lefebvre, A. Uzabiaga, Y.J. Shen, Z. Tan, Y.P. Cheng, W. Liu and H.Y.Ng, Water Sci. Tech. 64, (7), 1527,(2011).

8. S. Mulijani, K. Dahlan, A. Wulanawati, Int. J.Mater.Mech.Manuf., 2, (2014).

9. W.J. Ahn et al Electrochi. Act. 56, 7732 (2011).

10. Z.X. Liang, T.S. Zhao, J. Prabhuram, Electrochi. Acta 51, 6412 (2006).

11. J.M.Song, S.Y.Cha, W.M.Lee, J. Power Source, 94, (1) 78 (2001).

12. J.M. Moon, S Kondaveeti, B. Min, Fuel Cells, 15, (1) 230 (2015).

[RJC-1930/2017] 